\title{
GREENWASHING: DOS CONCEITOS À TENDÊNCIA DA LITERATURA CIENTÍFICA GLOBAL
}

\author{
Rafael Batista Ferreira ${ }^{1}$ \\ Ananda Helena Nunes Cunha ${ }^{2}$ \\ Carlos Eduardo Bento Barbosa ${ }^{3}$ \\ Mirza Seabra Toschi ${ }^{4}$
}

Resumo: Objetivou -se com a elaboração dessa pesquisa criar um alerta sobre as empresas greenwashing levantando conceitos do termo, o papel do sujeito ecológico frente esta prática, como surgem as empresas que o praticam e seus diagnósticos, além de trazer uma possível alternativa de inibi-las em nível nacional. Também, com intuito de provar a relação estreita entre ciência, tecnologia, sociedade e ambiente realizou-se uma análise cienciométrica do tema greenwashing. No geral, consolidou-se a hipótese da estreita relação entre ciência, tecnologia, sociedade e ambiente, evidenciando a importância deste estudo para a mudança dos hábitos de consumo da sociedade

Palavras-chave: Lavagem Verde; Cienciometria; Tecnologia; Sociedade. Ambiente.

\footnotetext{
${ }^{1}$ Universidade Estadual de Goiás (UEG); Faculdade Metropolitana de Anápolis (FAMA). E-mail: rafael_g3bf@hotmail.com

2 Universidade Estadual de Goiás (UEG).E-mail: analena23@gmail.com

${ }^{3}$ Universidade Estadual de Goiás (UEG). E-mail: cadu_eduard13@hotmail.com

${ }^{4}$ Universidade Estadual de Goiás (UEG). E-mail: mirza.seabra@gmail.com.
}

Revbea, São Paulo, V. 14, № 2: 215-233, 2019.

revista brasileira educação ambiental 


\section{Introdução}

O estudo realizado por Ricardo (2007) intitulado "Educação CTSA: obstáculos e possibilidades para sua implementação no contexto escolar", objetivou explorar fatores que constituem obstáculos para a implementação da educação CTSA (Ciência, Tecnologia, Sociedade e Ambiente) e levantar algumas alternativas para contornar tais fatores. No prólogo de seu estudo, o autor levanta a seguinte hipótese: A sociedade se encontra, bem ou mal, cada vez mais dependente dos avanços científicos e tecnológicos para a tomada de decisões comuns, individuais ou coletivas.

Levando em consideração a hipótese supracitada, o presente estudo científico busca fazer uma alerta para a sociedade sobre uma prática enganosa que advém do marketing verde e que possui como objetivo trazer a ilusão que determinada empresa detém preocupações ambientais quando de fato isso não ocorre: o greenwashing. Tal estratégia é comum no mundo dos negócios modernos, entretanto, produz consequências negativas para o meio ambiente como um todo. Para tanto, levantou-se os principais conceitos do temo greenwashing, o papel do sujeito ecológico frente esta prática, como surgem as empresas que o praticam e seus diagnósticos, além de trazer uma possível alternativa de inibi-las em nível nacional.

Além de utilizar da hipótese levantada por Ricardo (2007) a presente pesquisa visa provar sua veracidade. Para realizar tal prova elaborou-se um estudo cienciométrico sobre a temática greenwashing. A Cienciometria é o estudo dos aspectos quantitativos da ciência, e busca investigar tendências e vieses na literatura científica de determinado tema (FERREIRA et al., 2014; LOUZADA JUNIOR; FREITAS, 2011; VERBEEK; DEBACKERE; LUWEL, 2002). Estudos cienciométricos têm sido utilizados para avaliar a importância de um assunto, autor ou artigo, além de enfatizar as direções futuras e as contribuições de uma disciplina, cientista ou grupo de pesquisa, instituição ou país sobre os avanços científicos e tecnológicos (e.g. CARNEIRO; NABOUT; BINI, 2008; FERREIRA et al., 2014; NABOUT et al., 2012). Ademais, aos resultados cienciométricos obtidos na presente pesquisa foram inclusas correlações teóricas do comportamento tecnológico, social e ambiental buscando evidenciar como se dá a relação entre ciência, sociedade, tecnologia e ambiente.

\section{Conceitos do termo greenwashing}

Greenwashing é um termo que vem sendo adotado desde 2007 no mundo corporativo e aos poucos tem sido introduzido nas discussões sobre produtos. Sua melhor tradução seria "lavagem verde", ou mesmo "pincelada verde". O termo é designado quando uma empresa, organização não governamental (ONG), ou mesmo o próprio governo, propaga práticas ambientais positivas e, na verdade, possui atuação contrária ou neutra aos interesses e bens ambientais (RIBEIRO; EPAMINONDAS, 2010). 
Ao avaliar o efeito das empresas greenwashing no contexto do século XXI, Brito Junior e Giacomini Filho (2014) explicam que esse termo pejorativo é utilizado por ambientalistas para designar atitudes de "responsabilidade ambiental" promovidas por empresas e que, na verdade, não passam de ações de marketing visando passar uma melhor imagem socioambiental. Os autores ainda citam que uma empresa que empreenda anúncio abusivo sobre o meio ambiente, provavelmente está pensando em tirar proveito mercadológico e institucional, o que não se sustenta enquanto política de marketing ambiental, praticando, assim, o greenwashing.

Para Siano et al. (2017), o greenwashing tem sido associado exclusivamente com ações simbólicas, que tendem a desviar a atenção para questões menores fazendo com que as ações maiores em que há a falta de sustentabilidade sejam "mascaradas".

O termo greenwashing também pode ser definido como a intersecção de dois fortes comportamentos: o mau desempenho ambiental e comunicação positiva sobre tal desempenho ambiental (DELMAS; BURBANO, 2011 apud BRITO JUNIOR; GIACOMINI FILHO, 2014, p.96). Segundo o Greenpeace (2008), trata-se de uma manobra que usa a preservação ambiental como forma de apelo para convencer, distrair, iludir os consumidores sobre as práticas ambientais das empresas e os benefícios de um produto ou serviço, por meio de rotulagem do produto, na embalagem, em campanhas publicitárias (visual e escrita), em manuais técnicos na descrição do produto/serviço e/ou no processo produtivo, bem como outros meios para vender uma falsa ideia ou atributo. Dessa forma, o greenwashing está positivamente relacionada à confusão do consumidor a respeito dos argumentos usados pelas marcas (MOURA; POMPEO, 2015)

\section{O sujeito ecológico e sua responsabilidade frente às práticas greenwashing}

A Revolução Industrial no século XIX trouxe ao mercado consumidor grande desenvolvimento, transformando, por completo, as relações entre consumidores, fornecedores e Estado (PEREIRA e HORN, 2009). O aumento da produção trouxe consigo um aumento no consumo de uma forma nunca antes experimentada pela sociedade. Aceito e imposto rapidamente, este novo modelo de sistema econômico, denotado por capitalismo, foi implementado mediante diversos procedimentos subjetivos.

A população não percebia, e até hoje não percebe, uma manipulação do sistema econômico para que haja níveis de consumo exagerado, também conhecido como hiperconsumo, no qual traz consigo uma ótica distorcida da necessidade de bens de consumo. $O$ gasto excessivo em produtos supérfluos é a principal premissa do consumismo e do hiperconsumismo, comportamentos nos quais a necessidade de consumo torna-se uma compulsão ou uma patologia (MOURA; POMPEO, 2015). 
Desta forma, quando levado em consideração um ponto de vista mais "marxista", fica notório que o sistema capitalista é totalmente individualista, transformando o âmago da sobrevivência humana em suas necessidades. Tem-se utilizado recursos naturais para viver plenamente, porém com a questão do consumo exagerado de produtos, o apego aos bens, acaba desequilibrando o meio ambiente. Como consequência podemos prever que modo de desenvolvimento da economia do mercado capitalista trará a extinção de recursos naturais encontrados no planeta terra.

Entretanto, diferentemente de outrora, os consumidores têm se preocupado cada vez mais com o meio ambiente na hora de fazerem suas escolhas. Esse fato pode ser explicado pelo crescente número de sujeitos ecológicos na sociedade. Cresce a cada dia o número de pessoas que buscam consumir produtos oriundos de organizações com imagem e reputação, que transmitam confiança e responsabilidade social e ambiental. O novo perfil de consumidor/cliente está cada vez mais atento à gestão empresarial que alie estratégias, políticas e práticas, na busca por organizações com responsabilidade social e ambiental e que não pratiquem o greenwashing (SILVA; LOPES, 2014).

Segundo Carvalho (2010), sujeito ecológico é um modo de ser relacionado à adoção de um estilo de vida ecologicamente orientado. Trata-se de um conceito que dá nome àqueles aspectos da vida psíquica e social que são orientados por valores ecológicos. Podendo ainda ser descrito como um ideal ou uma utopia internalizado pelos indivíduos ou pessoas que adotam uma orientação ecológica em suas vidas.

Uma das funções inerentes a este indivíduo é o seu papel quanto educador ambiental (CARVALHO, 2010). O sujeito ecológico que assume esta responsabilidade retém o compromisso de certa consonância entre sua vida e sua causa, tornando sua vida pessoal uma espécie de laboratório de aprendizagem que antecipa a utopia de sociedade ecológica. Dessa forma é a partir das atitudes do sujeito ecológico que outros indivíduos da sociedade contemporânea compreendem a necessidade de mudança em seus hábitos diários, sobretudo na forma de consumo adotada. Ademais, deve-se levar em consideração que ainda não houve, por parte do consumidor, uma compreensão plena das implicações de seus atos de consumo, tanto no que se refere aos impactos no meio ambiente, como com relação ao seu poder de induzir e interferir na promoção do desenvolvimento (PEREIRA; AYROSA, 2004).

Ressalte-se que o ideal almejado pelo sujeito ecológico nem sempre é alcançado. Isso pode ser explicado por vários fatores, entre eles a escassez de oportunidades coletivas que facilitem e promovam um estilo de vida ecológico e a alta produtividade em que os produtos oferecidos hoje nos proporcionam, como por exemplo carro próprio e eletrodomésticos (CARVALHO, 2010).

Uma estratégia para contrapor tal paradigma é a utilização de produtos oriundos de empresas que possuem um apelo à conservação ambiental e que 
não detém de falácias utilizadas no marketing verde. Desta forma, cabe primeiramente ao sujeito ecológico, munido de um comportamento educacional, escolher tais empresas para o seu suprimento além de identificar e denunciar empresas que praticam o greenwashing.

\section{O Marketing Verde e os casos greenwashing}

Corroborando a premissa de que a quantidade de consumidores preocupados com o meio ambiente possui perspectiva de aumento, Lovato (2013) afirma que o desenvolvimento sustentável e, consequentemente, a noção de marketing verde, conhecido também como marketing ambiental ou marketing ecológico, nasceram a partir da conclusão de que não há mais como dissociar natureza e sociedade. Torna-se obrigado uma evolução conceitual e uma mudança de paradigma da frente de produção atual (SILVA e LOPES, 2014).

Segundo Boone e Kurtz (2001), o marketing verde é uma modalidade derivada do marketing básico o qual visa atender às necessidades daqueles clientes que possuem um comportamento diferenciado por se preocuparem com medidas sustentáveis e com danos à natureza. Trata-se da aplicação da promoção, produção e também na recuperação de produtos que são ecológicos e sensíveis ao meio ambiente.

Deve-se levar em consideração que para uma empresa ser considerada "verde" torna-se necessário a aplicação, em toda a sua conjuntura, de investimentos e ações ambientais, desde a fabricação e a produção de bens até as suas relações com clientes, fornecedores e funcionários. Entretanto, questões de custos, produtividade e fornecimento são alguns obstáculos que ainda representam um empecilho para que as organizações possam ser totalmente ecológicas (GUIMARÃES; VIANA; COSTA, 2015).

Se por um lado, a empresa pode diminuir custos reduzindo água ou energia, e reciclando e reutilizando materiais, por outro ela corre riscos de gastar mais na produção ou na fabricação de embalagens, entre outros fatores. Desta forma algumas empresas escolhem seguir um caminho mais fácil e se aproveitarem desse novo cenário se engajado em práticas de greenwashing (CHEN; CHANG, 2012; GUIMARÃES; VIANA; COSTA 2015; KEWALRAMANI; SOBELSOHN, 2012 apud MOURA; POMPEO, 2015, p. 3).

\section{Como identificar práticas de greenwashing?}

Com o intuito de fornecer aos sujeitos ecológicos subsídios para a identificação de falsas empresas "verdes" foram selecionados resultados de estudos que elaboraram diagnósticos sobre a possibilidade de uma empresa estar praticando greenwashing.

Os diagnósticos mostrados no Quadro 1 são oriundos da pesquisa conduzida por Ribeiro e Epaminondas (2010), no qual os autores se basearam 
em dados da Revista Veja publicada em dezembro de 2009. Nota-se que alguns diagnósticos como "palavras vazias" e "imagens sugestivas" são facilmente encontradas em propagandas nacionais. Já diagnósticos como "amigos imaginários" e "fala, mas não prova" são utilizados de formas mais astuta por empresas greenwashing e requer uma observação mais minuciosa do consumidor/cliente. Observa-se também no diagnóstico "falta de credibilidade" à utilização de produtos que são sustentáveis na sua fabricação, porém podem trazer riscos aos consumidores.

Quadro 1: Diagnósticos da prática de greenwashing levantados por Ribeiro e Epaminondas (2010)

\begin{tabular}{|c|}
\hline 1. Palavras vazias \\
\hline Uso de termos cujo significado é obscuro, como "eco-friendly", geralmente em Inglês. \\
\hline 2. Imagens sugestivas \\
\hline A foto sugere um feito impossível, como flores brotando do escapamento de um carro. \\
\hline 3. Amigos imaginários \\
\hline Selos que parecem fornecidos por órgãos independentes, mas são apenas parte da propaganda. \\
\hline 4. Relativo, mas não absoluto \\
\hline Ser mais "verde" que os concorrentes, pode não ser bom se os outros forem terríveis. \\
\hline 5. Falta de credibilidade \\
\hline O produto pode ser ecológico, o que não significa que seja seguro ou saudável. \\
\hline 6. Linguagem hermética \\
\hline Vocabulário ou dados que apenas os especialistas compreendem. \\
\hline 7. Fala, mas não prova \\
\hline
\end{tabular}

O Quadro 2 apresenta os resultados encontrados na pesquisa realizada por Lyon e Montgomery (2015) no qual foram citados os diagnósticos, sua definição, qual estudo o citou e exemplos práticos. 
Quadro 2: Diagnósticos da prática de greenwashing levantados por Lyon e Montgomery (2015)

\begin{tabular}{|c|c|c|c|}
\hline Diagnósticos & Definição & Referências* & Exemplos \\
\hline Ação e objeto & $\begin{array}{l}\text { Abismos entre as } \\
\text { ações e os objetivos } \\
\text { de uma organização }\end{array}$ & $\begin{array}{c}\text { Bromley e Powell } \\
\text { (2012) }\end{array}$ & $\begin{array}{l}\text { Os biocombustíveis são } \\
\text { adotados para reduzir o } \\
\text { aquecimento global, mas } \\
\text { não está claro que ajudem }\end{array}$ \\
\hline Gestão simbólica & $\begin{array}{c}\text { Abismos entre } \\
\text { promessas e ações }\end{array}$ & $\begin{array}{l}\text { Westphal e Zajac } \\
\text { (1994); Ramus e } \\
\text { Montiel (2005) }\end{array}$ & $\begin{array}{c}\text { As empresas prometem } \\
\text { proteger o ambiente, porém } \\
\text { não o fazem }\end{array}$ \\
\hline Efeito "impressão geral" & $\begin{array}{l}\text { Incapacidade de } \\
\text { avaliar atributos } \\
\text { individuais além de } \\
\text { uma impressão geral }\end{array}$ & $\begin{array}{c}\text { Thorndike } \\
\text { (1920); Russo, } \\
\text { Metcalf e } \\
\text { Stephens (2004) }\end{array}$ & $\begin{array}{l}\text { O consumidor aprende que } \\
\text { os produtos de uma } \\
\text { empresa são orgânicos, por } \\
\text { isso também assume que } \\
\text { eles devem usar energia } \\
\text { renovável }\end{array}$ \\
\hline Agrupamento & $\begin{array}{l}\text { Tomar a mesma ação } \\
\text { dispendiosa de um } \\
\text { indivíduo mais capaz } \\
\text { para parecer idêntico }\end{array}$ & $\begin{array}{c}\text { Spence (1973); } \\
\text { Delmas e Montes } \\
\text { Sancho (2010) }\end{array}$ & $\begin{array}{c}\text { As empresas aderem a } \\
\text { programas voluntários, mas } \\
\text { não mudam de } \\
\text { comportamento }\end{array}$ \\
\hline Divulgação seletiva & $\begin{array}{c}\text { Divulgação de } \\
\text { informações positivas } \\
\text { ao negar informações } \\
\text { negativas }\end{array}$ & $\begin{array}{l}\text { Lyon e Maxwell } \\
\text { (2011); Lyon e } \\
\text { Montgomery } \\
\text { (2013) }\end{array}$ & $\begin{array}{l}\text { "Os secadores de mãos } \\
\text { ajudam a proteger o meio } \\
\text { ambiente. Eles evitam que } \\
\text { as árvores sejam usadas } \\
\text { para toalhas de papel" }\end{array}$ \\
\hline Falsificação & $\begin{array}{l}\text { Falsificações para } \\
\text { enganação de } \\
\text { consumidores }\end{array}$ & $\begin{array}{c}\text { Lacker e } \\
\text { Weinberg (1989); } \\
\text { Hamilton e } \\
\text { Zilberman (2006) }\end{array}$ & $\begin{array}{l}\text { Etiquetas ecológicas } \\
\text { fraudulentas }\end{array}$ \\
\hline Superioridade implícita & $\begin{array}{c}\text { Sugere que um } \\
\text { produto é melhor do } \\
\text { que outro sem provas } \\
\text { concretas }\end{array}$ & Snyder (1989) & $\begin{array}{l}\text { "Nenhum outro produto é } \\
\text { tão eficaz" }\end{array}$ \\
\hline
\end{tabular}

${ }^{*}$ Apud Lyon e Montgomery (2015, p. 227).

Já o Quadro 3 apresenta os dados obtidos na dissertação produzida por Pagotto (2013) que teve por objetivo a verificação de alguns diagnósticos da aplicação de práticas greenwashing. Para a construção deste quadro de referências, o autor selecionou 3 obras: a dos estadunidenses Bruno e Karliner (2002), a do britânico Gillspie (2008) e a do australiano Pearse (2012). 
Quadro 3: Diagnósticos da prática de greenwashing levantados por Pagotto (2013)

\begin{tabular}{|c|c|c|c|c|}
\hline Pressupostos & Manifestação & $\begin{array}{c}\text { Bruno e Karliner, } \\
2002^{*} \\
\end{array}$ & $\begin{array}{c}\text { Gillspie, } \\
2008^{*} \\
\end{array}$ & $\begin{array}{c}\text { Pearse, } \\
2012^{*}\end{array}$ \\
\hline \multirow{4}{*}{$\begin{array}{l}\text { Discursividade: o } \\
\text { que a } \\
\text { organização diz }\end{array}$} & $\begin{array}{c}\text { Manipular o discurso ambientalista com } \\
\text { exageros, afirmações irrelevantes, } \\
\text { genéricas ou pretensões irreais. }\end{array}$ & $\mathbf{x}$ & $\mathbf{x}$ & $\mathbf{x}$ \\
\hline & $\begin{array}{c}\text { Omitir impactos ambientais negativos da } \\
\text { operação de seu negócio, destacando } \\
\text { apenas os positivos. }\end{array}$ & $\mathbf{x}$ & & \\
\hline & $\begin{array}{l}\text { Mentir, usar dados falsos, fazer } \\
\text { afirmações que distorcem a realidade ou } \\
\text { que não podem ser provadas. }\end{array}$ & & $\mathbf{x}$ & \\
\hline & Utilizar jargão técnico incompreensível. & & $\mathbf{x}$ & \\
\hline \multirow{4}{*}{$\begin{array}{l}\text { Estética: o que a } \\
\text { organização } \\
\text { mostra }\end{array}$} & $\begin{array}{l}\text { Usar imagens, sons ou vídeos } \\
\text { ambientais sedutores }\end{array}$ & $\mathbf{x}$ & $\mathbf{x}$ & $\mathbf{x}$ \\
\hline & $\begin{array}{l}\text { Omitir imagens da operação dos } \\
\text { negócios. }\end{array}$ & $\mathbf{x}$ & & \\
\hline & $\begin{array}{l}\text { Destacar parceiros que compartilham } \\
\text { compromissos ecológicos. }\end{array}$ & & $\mathbf{x}$ & $\mathbf{x}$ \\
\hline & $\begin{array}{c}\text { Utilizar uma identidade visual } \\
\text { ambientalista } \\
\end{array}$ & $\mathbf{x}$ & $\mathbf{x}$ & $\mathbf{x}$ \\
\hline \multirow{6}{*}{$\begin{array}{l}\text { Ações: o que a } \\
\text { organização faz }\end{array}$} & $\begin{array}{l}\text { Desviar atenção para projetos } \\
\text { socioambientais paralelos. }\end{array}$ & $\mathbf{x}$ & & $\mathbf{x}$ \\
\hline & $\begin{array}{l}\text { Tratar obrigações legais como } \\
\text { investimentos em meio ambiente. }\end{array}$ & $\mathbf{x}$ & & \\
\hline & $\begin{array}{l}\text { Alegar custo excessivo de medidas } \\
\text { ecologicamente mais corretas. }\end{array}$ & $\mathbf{x}$ & & \\
\hline & $\begin{array}{l}\text { Evitar intervenções externas alegando } \\
\text { que resolverão o problema sozinhos. }\end{array}$ & $\mathbf{x}$ & & \\
\hline & Infiltrar-se na comunidade ambientalista. & $\mathbf{x}$ & $\mathbf{x}$ & $\mathbf{x}$ \\
\hline & $\begin{array}{l}\text { Incentivar clientes a contribuírem, } \\
\text { estimular a propositura de novas formas } \\
\text { de tornar a empresa mais "verde". }\end{array}$ & & & $\mathbf{x}$ \\
\hline \multirow{3}{*}{$\begin{array}{l}\text { Portfolio: o que e } \\
\text { como a } \\
\text { organização } \\
\text { vende }\end{array}$} & $\begin{array}{c}\text { Vender produtos "ecológicos" que fazem } \\
\text { mal às pessoas ou ao meio ambiente. }\end{array}$ & $\mathbf{x}$ & $\mathbf{x}$ & $\mathbf{x}$ \\
\hline & $\begin{array}{c}\text { Anunciar produtos "verdes" com } \\
\text { celebridades. }\end{array}$ & & & $\mathbf{x}$ \\
\hline & Criar eco-lojas. & & & $\mathbf{x}$ \\
\hline
\end{tabular}

* Apud Pagotto (2013, p. 76).

Ao levarmos em consideração os diagnósticos oriundos dos três quadros apresentados anteriormente, observa-se que empresas greenwashing utilizam de conceitos ambientais para construção de uma imagem pública confiável, que, contudo, não condizem com a real gestão, muitas vezes negativa e causadora de degradação ambiental. Seguem exemplos de propagandas 
dessas empresas: Carros que não poluem o meio ambiente, sabões que se denominam "ecologicamente corretos" devido sua cor verde, geladeira $100 \%$ ecológica, produtor rural orgulhoso por "alimentar a nação" ao ver sua plantação de soja "saudável" ao utilizar agrotóxico, produtos plásticos sustentáveis, entre outros.

\section{Aliado político nacional}

Em 1970, é criado o CONAR - Código Brasileiro de Autorregulamentação Publicitária - em função de uma ameaça ao setor: no final dos anos 1970, o governo federal pensava em sancionar uma lei criando uma espécie de censura prévia à propaganda. Criada e constituída por publicitários e profissionais de outras áreas, o CONAR é uma organização nãogovernamental que visa promover a liberdade de expressão publicitária e defender as prerrogativas constitucionais da propaganda comercial (CONAR, 2017).

Uns dos objetivos do CONAR é impedir que a publicidade enganosa ou abusiva cause constrangimento ao consumidor ou a empresas, garantindo 0 cumprimento da ética publicitária que possui os seguintes preceitos básicos:

- todo anúncio deve ser honesto e verdadeiro e respeitar as leis do país;

- deve ser preparado com o devido senso de responsabilidade social, evitando acentuar diferenciações sociais;

- deve ter presente a responsabilidade da cadeia de produção junto ao consumidor;

- deve respeitar o princípio da leal concorrência e

- deve respeitar a atividade publicitária e não desmerecer a confiança do público nos serviços que a publicidade presta.

Fialho, Marquesan e Souza (2015) afirmam em sua pesquisa que, desde agosto de 2011, o CONAR busca o cumprimento de regulamentações sobre o uso do tema sustentabilidade ambiental em propagandas, por meio da inserção, em seu código de ética, do Anexo "U" referente aos apelos de sustentabilidade. A medida visa impedir que publicidade enganosa ou abusiva cause constrangimento ao consumidor ou o induza ao erro, impedindo assim que os anúncios enalteçam possíveis atributos sustentáveis de serviços e produtos sem a devida comprovação de práticas que minimizem o impacto ao meio ambiente.

O CONAR atende a denúncias de consumidores, autoridades, dos seus associados ou ainda formuladas pela própria diretoria. Feita a denúncia, o Conselho de Ética da organização se reúne e a julga, garantindo amplo direito de defesa ao acusado. Se a denúncia tiver procedência, o CONAR recomenda aos veículos de comunicação a suspensão da exibição da peça ou sugere correções à propaganda. Pode ainda advertir anunciante e agência.

revista brasileira educação ambiental 
$\mathrm{Na}$ pesquisa realizada por Fialho, Marquesan e Souza (2015) quantificou-se, em um período entre 2011 a 2015, os processos alterados (peças publicitárias alteradas devido à falta de clareza do anúncio exposto) e os sustados (peças publicitárias excluídas da mídia devido não equivalerem à verdade ou provocarem algum tipo de constrangimento para o consumidor) devido à atuação do CONAR. Os autores afirmam que dentre os anúncios expostos (15 alterados e dois sustados), dois classificados como alterados foram bastante evidenciados na mídia e os dois sustados foram considerados casos explícitos de greenwashing. Estes quatro exemplos estão no Quadro 4.

Quadro 4. Principais processos alterados e sustados no período entre 2011 a 2015 pelo CONAR

\begin{tabular}{|c|c|c|c|c|c|}
\hline Casos & \begin{tabular}{|c|} 
Propaganda \\
e meio de \\
comunicação
\end{tabular} & Assunto & $\begin{array}{c}\text { Princípio } \\
\text { descumprido }\end{array}$ & $\begin{array}{l}\text { Defesa do } \\
\text { anunciante }\end{array}$ & $\begin{array}{l}\text { Motivo da } \\
\text { decisão do } \\
\text { CONAR }\end{array}$ \\
\hline \multirow{2}{*}{ 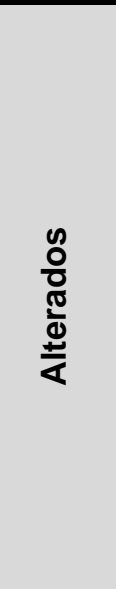 } & $\begin{array}{c}\text { OMO } \\
\text { concentrado } \\
\text { ajuda a } \\
\text { reduzir o } \\
\text { consumo de } \\
\text { água (anúncio } \\
\text { em TV) }\end{array}$ & $\begin{array}{l}\text { Anúncio afirma } \\
\text { que o uso do } \\
\text { produto ajuda a } \\
\text { reduzir o consumo } \\
\text { de água em } \\
\text { milhões de litros } \\
\text { por ano }\end{array}$ & $\begin{array}{c}\text { Veracidade, } \\
\text { concretude, } \\
\text { comprovação } \\
\text { e fontes }\end{array}$ & $\begin{array}{l}\text { Demonstraram } \\
\text { por meio de } \\
\text { cálculos a } \\
\text { economia de } \\
\text { mais de um } \\
\text { milhão de litro } \\
\text { de água }\end{array}$ & $\begin{array}{l}\text { Não comprovação } \\
\text { da precisão do } \\
\text { cálculo }\end{array}$ \\
\hline & $\begin{array}{l}\text { Achocolato } \\
\text { Orgânico } \\
\text { Native - aço } \\
\text { reciclável } \\
\text { (menção na } \\
\text { embalagem) }\end{array}$ & $\begin{array}{l}\text { Embalagem do } \\
\text { Achocolatado } \\
\text { Orgânico Native } \\
\text { faz menção } \\
\text { especial ao "Aço - } \\
\text { Reciclável - } \\
\text { Ecológico" }\end{array}$ & $\begin{array}{l}\text { Veracidade, } \\
\text { relevância, } \\
\text { exatidão, } \\
\text { clareza, } \\
\text { comprovação } \\
\text { e fontes }\end{array}$ & $\begin{array}{c}\text { Alusão ao } \\
\text { documento da } \\
\text { ABNT, } \\
\text { intitulado } \\
\text { Simbologia de } \\
\text { Identificação de } \\
\text { Materiais }\end{array}$ & $\begin{array}{c}\text { Excluir o termo } \\
\text { "ecológico". O aço } \\
\text { não é ecológico, e } \\
\text { a informação não } \\
\text { pode induzir o } \\
\text { consumidor ao erro }\end{array}$ \\
\hline \multirow[b]{2}{*}{ 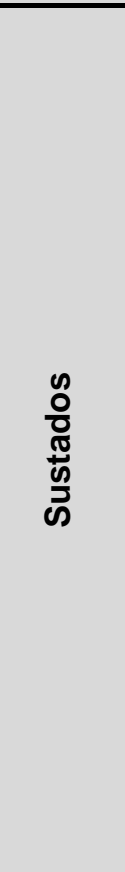 } & $\begin{array}{l}\text { Água Mineral } \\
\text { Rocha Branca } \\
\text { (anúncio em } \\
\text { spot de rádio) }\end{array}$ & $\begin{array}{l}\text { A empresa Água } \\
\text { Mineral Rocha } \\
\text { Branca, por meio } \\
\text { de um selo verde } \\
\text { garante que a } \\
\text { industrialização da } \\
\text { água não gera } \\
\text { impacto ao meio } \\
\text { ambiente }\end{array}$ & $\begin{array}{l}\text { Veracidade, } \\
\text { exatidão, } \\
\text { clareza, } \\
\text { comprovação, } \\
\text { fontes, } \\
\text { absoluto, } \\
\text { concretude }\end{array}$ & $\begin{array}{c}\text { A empresa não } \\
\text { declarou } \\
\text { defesa, } \\
\text { somente } \\
\text { cancelou a } \\
\text { exibição do } \\
\text { spot }\end{array}$ & $\begin{array}{c}\text { Não existem } \\
\text { compensações } \\
\text { plenas que anulem } \\
\text { os impactos } \\
\text { socioambientais }\end{array}$ \\
\hline & $\begin{array}{l}\text { APAS - } \\
\text { Vamos tirar o } \\
\text { planeta do } \\
\text { sufoco } \\
\text { (campanha } \\
\text { em mídias } \\
\text { diversas) }\end{array}$ & $\begin{array}{l}\text { Divulgação da } \\
\text { vedação da } \\
\text { distribuição } \\
\text { gratuita de sacolas } \\
\text { plásticas nos } \\
\text { supermercados } \\
\text { como algo } \\
\text { benéfico ao meio } \\
\text { ambiente, } \\
\text { tachando as } \\
\text { sacolas como } \\
\text { descartáveis }\end{array}$ & $\begin{array}{l}\text { Veracidade, } \\
\text { concretude, } \\
\text { exatidão e } \\
\text { clareza }\end{array}$ & $\begin{array}{c}\text { Enviadas } \\
\text { explicações } \\
\text { técnicas, e } \\
\text { estudos de } \\
\text { órgãos oficiais } \\
\text { que validariam } \\
\text { suas } \\
\text { informações }\end{array}$ & $\begin{array}{l}\text { A campanha se } \\
\text { aproveita da } \\
\text { credulidade dos } \\
\text { consumidores, } \\
\text { denegrindo a } \\
\text { imagem das } \\
\text { sacolas plásticas. } \\
\text { As sacolas devem } \\
\text { ser tachadas como } \\
\text { reutilizáveis }\end{array}$ \\
\hline
\end{tabular}

Fonte: Baseado em Fialho, Marquesan e Souza (2015). 


\section{A pesquisa científica e o greenwashing}

O levantamento da literatura publicada para a realização da análise cienciométrica foi realizado utilizando o banco de dados publicado no sítio do "Thomson ISI" (ISI WEB OF KNOWLEDGE, 2017). Esta base de dados foi utilizada devido a sua abrangência quanto ao número de publicações e qualidade das revistas científicas indexadas (LIMA-RIBEIRO et al., 2007)

Foi realizada uma busca de todos os trabalhos que possuía no título, abstract e keywords a palavra greenwash ${ }^{*}$. O uso do asterisco na busca indica que qualquer término da palavra pode ser aceito, garantindo a inclusão do termo no singular (greenwash), no plural (greenwashes), no passado (greenwashed) e no gerúndio (greenwashing).

Os trabalhos foram analisados a partir de 1993, primeiro ano de registro para o termo, até 2016. Desconsiderou-se o ano de 2017, ano da realização da pesquisa, por se tratar de um ano corrente. As seguintes informações foram obtidas para cada artigo: a) Ano de publicação, b) Tipo de publicação, c) Nome do periódico em que o trabalho foi publicado, d) Área de concentração e e) País de publicação.

De acordo com o levantamento realizado, foram encontradas 139 publicações. O primeiro trabalho sobre greenwashing foi publicado em 1993 (Figura 1), porém somente a partir do ano de $2008(n=8)$ obteve-se estabilidade no crescimento anual de publicações. Se levarmos em consideração a importância que o Greenpeace possui na formação de opiniões socioambientais, podemos atribuir esse fato à publicação em 2008 do livro intitulado "Greenpeace book of greenwash" pela instituição, e que possui como objetivo a elucidação da temática greenwashing. Observa-se também que nos anos de 1994, 1995, 1996, 2001 e 2006 não se constatou publicações sobre a temática, entretanto, soma-se 10 anos (2007 a 2016) sem que haja ausência na publicação anual sobre greenwashing. Considerando todos os anos foi possível observar um aumento de trabalhos sobre o greenwashing seguindo um ajuste quadrático $\left(R^{2}=0.9151 ; p<0,01\right)$. $O$ maior número de trabalhos publicados sobre o tema foi observado em $2014(n=21)$. 


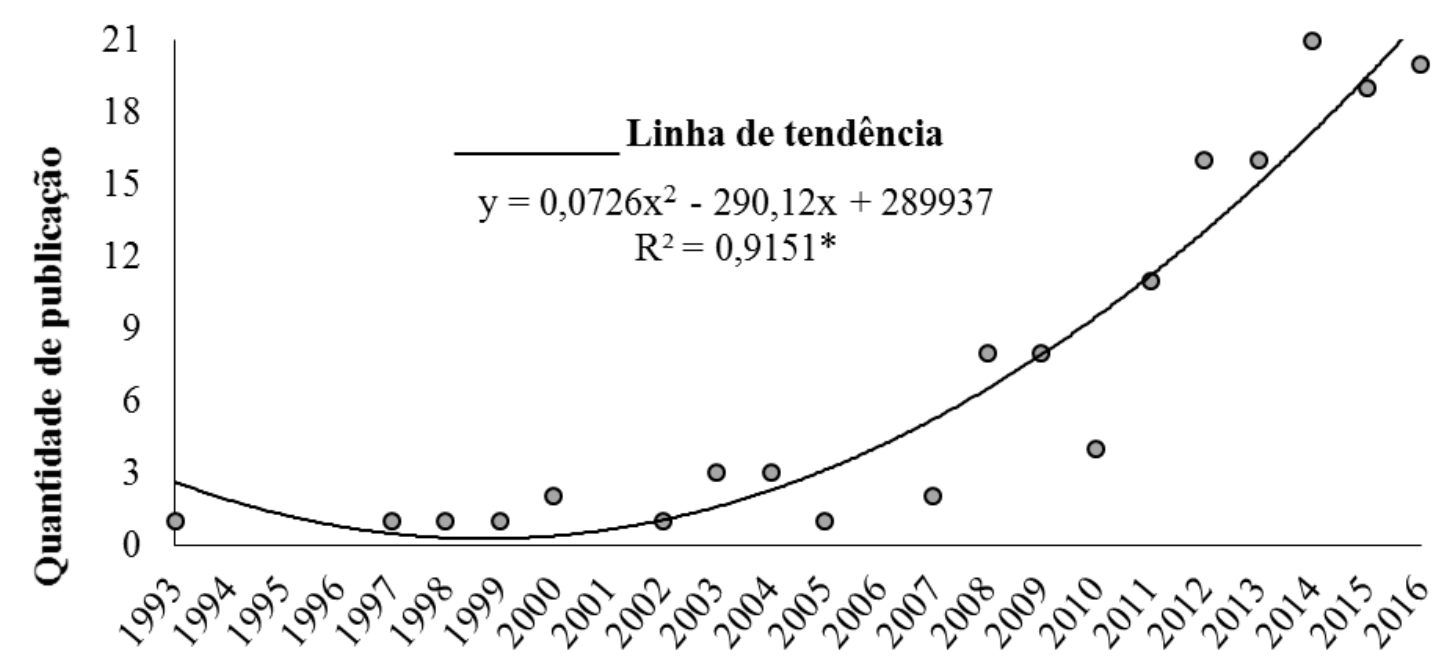

Ano

Figura 1: Número de trabalho sobre o greenwashing ao longo dos anos $(n=139)$. Publicações de 1993 a 2016. * Significativo a 1\% de probabilidade pelo Teste F.

A maioria dos trabalhos ( $n=99$, ou $71,22 \%$ do total de publicações) foi apresentada em forma de artigo, seguida de "Anais" ( $n=21$ ou $15,11 \%$ do total de publicações). Outros tipos de trabalhos ocorreram menos de nove vezes e juntos totalizaram 23 publicações (13,77\% do total de publicações).

Os trabalhos analisados foram publicados em 123 periódicos diferentes, porém, a maior parte $(\mathrm{n}=111$ periódicos) continha apenas uma publicação cada, totalizando $90,65 \%$ das publicações, o que pode refletir que há grande aceitabilidade por parte das revistas sobre o tema greenwashing. Por outro lado, 13 trabalhos $(9,35 \%$ do total de publicação) foram publicados no Periódico "Journal of Business Ethics" (Revista Ética nos Negócios), como observado na Figura 2. Macias-Chapula (1998) e Vanti (2002) afirmam que o periódico no qual o trabalho foi publicado é um dos critérios, dentre outros, para avaliação do contexto em que se insere o campo do conhecimento em avaliação. Desta forma, fica subtendido a preocupação da ciência pelo greenwashing no empreendedorismo. 


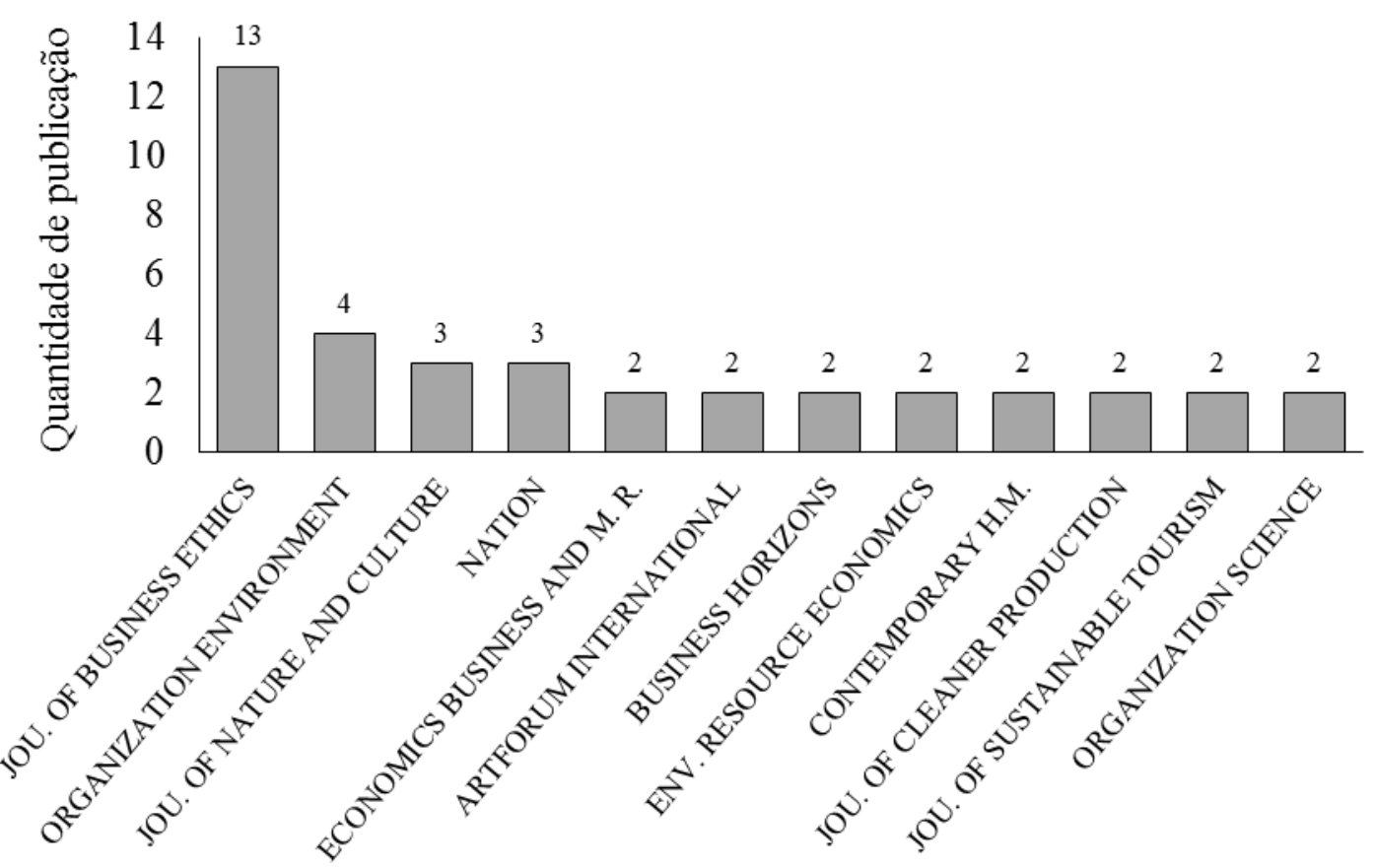

Título do periódico

Figura 2: Principais Periódicos de publicação dos trabalhos sobre greenwashing.

Corroborando o fato de que a prática do greenwashing afeta a economia de uma empresa, sociedade e o meio ambiente observa-se na Figura 3 que as áreas do conhecimento da maioria das publicações foram: Negócios e Economia ( $n=66$, ou $47,48 \%$ do total de publicações), Ciências Sociais $(n=25$, ou $20,14 \%$ do total de publicações) e Ecologia ambiental ( $n=27$, ou $19,42 \%$ do total de publicações).

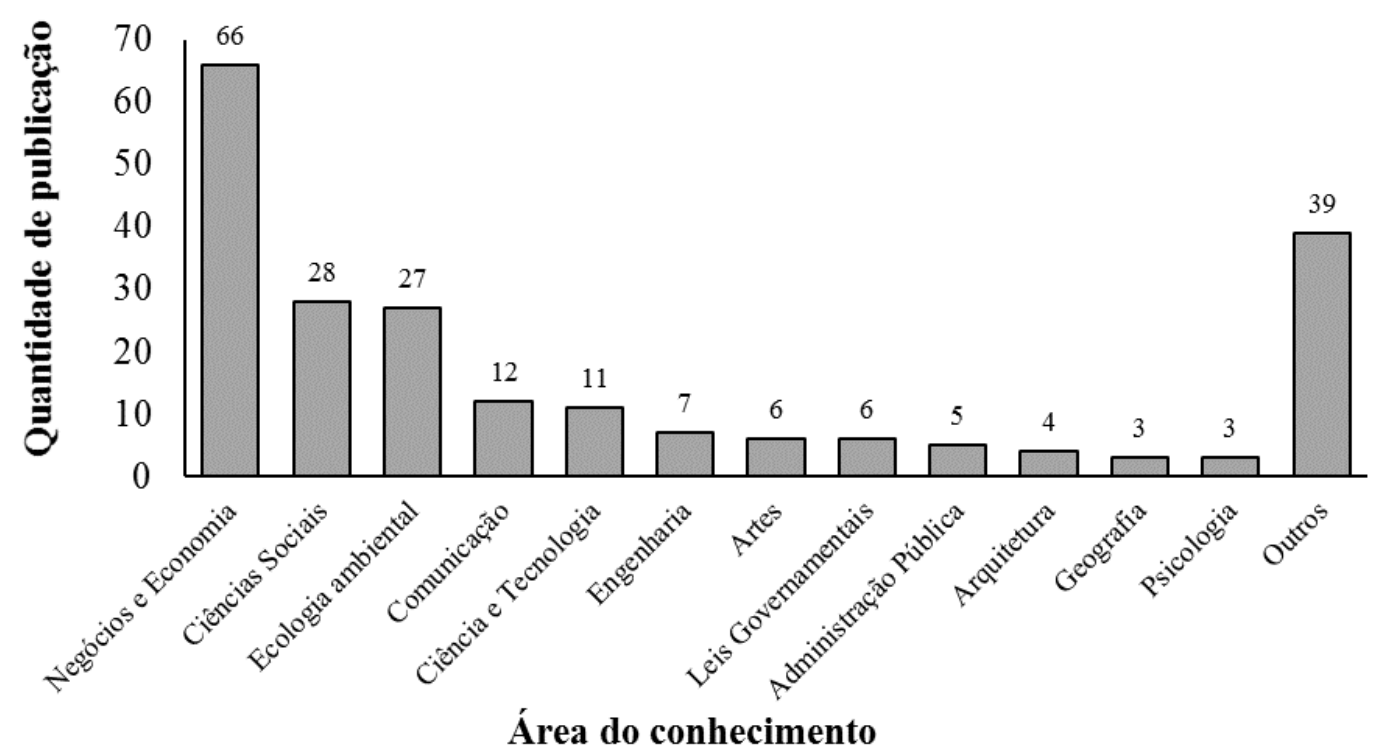

Figura 3: Áreas de publicação dos trabalhos sobre greenwashing.

Revbea, São Paulo, V. 14, № 2: 215-233, 2019. 
Através da Figura 4 pode ser observado que os cinco países (Estados Unidos, Inglaterra, Canadá, França e Alemanha) que mais publicaram sobre a temática greenwashing são desenvolvidos. Tal fato pode ser justificado pelo padrão dos consumidores nestes países. Sabe-se que em países desenvolvidos tem-se um nível de consumo maior que em países em desenvolvimento, entretanto, o padrão de consumo dos nestes países tem se invertido, ou seja, enquanto os desenvolvidos reduziram seu consumo os em desenvolvimento tendem a aumentar. Segundo a PETROBRAS (2017), ao avaliar o consumo de energia, concluiu que os países desenvolvidos, que se apresentavam como os maiores consumidores de petróleo no mundo tradicionalmente, já não vêm registrando crescimento significativo em sua demanda. Por outro lado, desde os anos 1990, o consumo dos países em desenvolvimento vem triplicando em comparação com 0 das nações desenvolvidas, sobretudo pela melhora no nível de vida em função da expansão das atividades econômicas, o que elevou o consumo de energia.

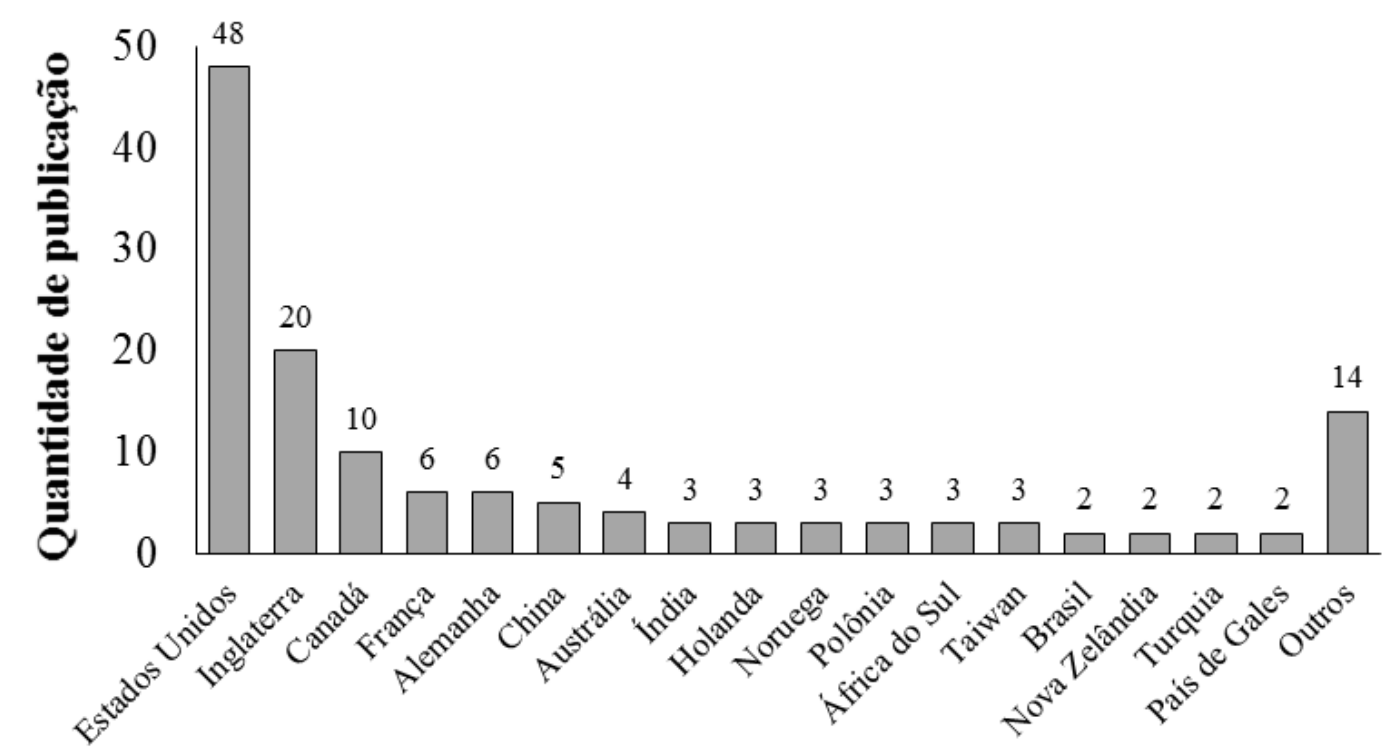

País

Figura 4. Quantidade de publicação de trabalhos sobre greenwashing por país.

O maior número de publicações por parte dos EUA (34,53\%), também é reflexo do investimento em infraestrutura e financiamento de pesquisas, não apenas por instituições públicas, mas também por empresas privadas e ONGs, além do fato da criação de diversos programas de apoio às iniciativas científicas (PACHECO, 2011). 


\section{Conclusões}

Grande parte dos produtos utilizados atualmente por nossa sociedade são prejudiciais ao meio ambiente, sendo impossível, pelo menos no estado atual da tecnologia, serem totalmente sustentáveis em nível ambiental como, por exemplo, os automóveis, cosméticos e sabões líquidos. Todavia o objetivo dessa pesquisa não foi fazer apologia ao uso de tais produtos, mas sim trazer elucidações de como algumas empresas utilizam de forma enganosa propagandas "verdes" ou mesmo apontando uma pequena melhora como a "solução final", quando de fato estamos muito aquém de viver e de consumir de forma sustentável.

Da mesma forma como muitas empresas têm buscado alcançar a sustentabilidade, procurando contribuir para um mundo melhor, há também muitas que perceberam a repercussão da sustentabilidade na era que vivemos e se utilizam dessa fragilidade para praticar o greenwashing.

Várias instituições parecem mais dedicadas em passar uma imagem de empresa preocupada com aspectos socioambientais do que efetivamente estão (LINS; SILVA, 2009). Mas por que exercer tal comportamento? Existem várias razões possíveis para essa tendência emergente, se destacando os potenciais benefícios que uma empresa pode obter em termos de desempenho financeiro (JONSEN et al., 2015) e capital de reputação (ARAS; CROWTHER, 2011).

Em países em desenvolvimento, como é o caso do Brasil, onde o descrédito com o Estado assim como com as práticas sociais e ambientais das empresas aumentam, tem-se a necessidade do surgimento de consumidores com maior percepção da falta de comprometimento das empresas no cumprimento de normas e diretrizes voltadas para a sustentabilidade e o respeito às relações humanas de consumo.

Nesse contexto, ressalte-se o importante papel dos sujeitos ecológicos e da sociedade civil organizada (especialmente sindicatos e organizações não governamentais, como é o caso do CONAR) que, com o advento da globalização da informação, proporcionada pelas tecnologias da comunicação, notadamente da internet, podem atuar globalmente com influência sobre os Estados e as empresas. Com vistas a combater condutas que fogem à ética publicitária, o CONAR tem se apresentado como um aliado importante e eficaz, evitando assim que as empresas pratiquem o greenwashing.

Entretanto, mudanças no tipo e quantidade de consumo assim como na sustentabilidade ambiental das empresas requer tempo, além de ser uma tarefa difícil de executar, pois esses aspectos demandam mudanças na estrutura social, em nossas formas de ver o mundo e de lidar com o consumo. Ressalte-se que várias pesquisas científicas demonstram que o planeta não pode esperar por mais tanto tempo e essas atitudes têm que começar a se tornarem reais, pois todos nós seremos vítimas de nossas atitudes impensadas de consumo.

Torna-se necessário entender melhor esse abismo que existe entre os produtos que consumimos e a sustentabilidade ambiental para que possam

revista brasileira educação ambiental 
surgir novos estudos científicos e, posteriormente, novas tecnologias que se agreguem ao consumo sustentável, sendo a prática do greenwashing prejudicial a esse entendimento.

Em relação às análises cienciométricas realizadas neste trabalho considera-se que o aumento de publicações ao longo dos anos a respeito do greenwashing é um indicativo do acréscimo de pesquisadores interessados nesse ramo de estudo, bem como de seu progresso científico e tecnológico, considerando que o número de publicações é uma das medidas mais utilizadas para quantificar o progresso e a evolução da ciência.

Os dados evidenciados entre ciência e a temática greenwashing confirmam o fato de que os desenvolvimentos científicos, técnicos, sociais e ambientais estão cada vez mais em relações estreitas e múltiplas. Desta forma, fica evidenciado através desses estudos quantitativos das atividades científicas, que a ciência pode ser um instrumento aplicado ao desenvolvimento de políticas públicas.

Outro aspecto da ciência que tem que se levar em consideração é a promoção de práticas de greenwashing por pesquisas científicas, ainda que de forma indireta. Vários trabalhos científicos vêm sendo publicados sobre a temática marketing verde e como obter lucros e sustentabilidade empresarial ao adotá-la (e.g. GONZAGA, 2005; JÖHR, 1994; MAKOWER, 2009; OTTMAN, 2012; PINHEIRO, 2015;), porém, parte destes estudos não levam em consideração a possibilidade da fomentação de práticas de greenwashing.

Um exemplo pode ser visto no estudo conduzido por Pinheiro (2015), no qual avaliou-se algumas das estratégias de Marketing Verde tendo como exemplo uma grande empresa de cosmético brasileira, explicando inicialmente os conceitos de Marketing, Estratégia empresarial, Marketing verde e Sustentabilidade e concluindo que tal empresa possui rentabilidade aceitável. O fato de um produto ser mais sustentável do que outro com a mesma função não quer dizer que o mesmo seja ecologicamente correto. Embora possa ser o primeiro passo rumo à sustentabilidade ambiental tal afirmação é falsa e pode ser entendida como um exemplo da prática de greenwashing.

Levando em consideração a veracidade da hipótese levantada por Ricardo (2007), apresentada na introdução deste estudo e comprovada por análises cienciométrica, podemos inferir que a presente pesquisa trouxe para a sociedade contemporânea uma reflexão sobre as atuais relações de consumo e sua devastadora consequência ambiental. Também podemos afirmar que para a solução da problemática ambiental, causada pelos níveis e formas de consumo atuais, cabe a civilização conscientizar da importância do resgate do controle nas relações de consumo, a fim de desenvolver sustentavelmente a natureza que nos cerca. Destarte, quando identificamos empresas greenwashing e não utilizamos seus produtos, pelo contrário a denunciamos, estamos adotando uma prática de consumo consciente concernente de um educador ambiental e consequentemente promovemos equilíbrio social e ecológico, em defesa ao meio ambiente ameaçado.

Revbea, São Paulo, V. 14, № 2: 215-233, 2019. 


\section{Referências}

ARAS, G., CROWTHER, D. Governance and social responsibility: International perspectives. New York: Palgrave Macmillan, 2011. 352 p.

BOONE, L.E.; KURTZ, D.L. Contemporary marketing. Orlando: The Dryden Press, 2001.669p.

BRITO JUNIOR, A.; GIACOMINI FILHO, G. Greenwashing e as organizações no contexto do Século XXI. RMS- Revista Metropolitana de Sustentabilidade, v.4, n.1, p.95-106, 2014.

CARNEIRO, F. M.; NABOUT, J. C.; BINI, L. M. Trends in the scientific literature on phytoplankton. Revista Limnology, v.9, n.2, p.53-158, 2008.

CARVALHO, I.C.M. Educação ambiental: a formação do sujeito ecológico. São Paulo: Editora Cortez, 5.ed., 2010.

CHEN, Y.S.; CHANG, C.H. Greenwash and Green Trust: The Mediation Effects of Green Consumer Confusion and Green Perceived Risk. Journal of Business Ethics, v.114, n.3, p.489-500, 2012.

CONAR- Código Brasileiro de Autorregulamentação Publicitária. Sobre o CONAR. 2017. Disponível em: <http://www.conar.org.br/>. Acesso em: 15 fev. 2017.

FERREIRA; R.B., BORGES NETO; A.C.; NABOUT, J.C.; JESUS; F.F.; CAETANO; J.M.; TEIXEIRA, I.R. Tendências na literatura científica global sobre o biodiesel: Uma análise cienciométrica. Bioscience. Journal., Uberlândia, v.30, supplement.2, p.547-554, 2014.

FIALHO, L.S.; MARQUESAN, F.F.S.; SOUZA, L. Greenwashing: crítica aos apelos "sustentáveis" das organizações nos meios de comunicação publicitários. SINGEP- IV. Anais... São Paulo, 2015. 14p.

GONZAGA, C.A.M. Marketing verde de produtos florestais: teoria e prática. Revista Floresta, v.35, n.2, p.353-368, 2005.

GREENPEACE. Greenpeace book of greenwash. 2008. 36p. Disponível em: $<$ http://research.greenpeaceusa.org/?a=view\&d=4519 >. Acesso em: 20 fev. 2017.

GUIMARÃES, C.; VIANA, L.S.; COSTA, P.H.S. Os desafios da consciência ambiental: o marketing verde em questão. Cadernos de Aulas do LEA, n.4, p.94-104, 2015.

ISI WEB OF KNOWLEDGE. Banco de dados publicado no sítio do "Thomson ISI". 2017. Disponível em: <http://isi9.isiknowledge.com>. Acesso em: 20 jan. 2017.

JÖHR, H. O verde é negócio. 3 ed, São Paulo: Saraiva, 1994. 191p.

JONSEN, K.; GALUNIC, C.; WEEKS, J.; BRAGA, T. Evaluating espoused values: Does articulating values pay off? European Management Journal, v.33, n.5, p.332-340, 2015. 
LIMA-RIBEIRO, M.S.; NABOUT, J.C.; PINTO, M.P.; MOURA, I.O.; MELO, T.L.; COSTA, S.S.; RANGEL, T.F.L.V.B. Análise cienciométrica em ecologia de populações: importância e tendências dos últimos 60 anos. Acta Scientiarum Biological Sciences, Maringá, v.29, n.1, p.39-47, 2007.

LINS, L.S.; SILVA, R.N.S. Responsabilidade Sócio-Ambiental ou Greenwash: uma avaliação com base nos relatórios de sustentabilidade ambiental. Revista Sociedade, Contabilidade e Gestão, Rio de Janeiro, v.4, n.1, p.91-105, 2009.

LOUZADA JUNIOR, P.; FREITAS, M.V.C. A Revista Brasileira de Reumatologia nos últimos dez anos - uma visão baseada em Cienciometria. Revista Brasileira de Reumatologia, São Paulo, v.51, n.1, p.1-6, 2011.

LOVATO, M. Greenwashing no Brasil: quando a sustentabilidade ambiental se resume a um rótulo. Revista Eletrônica do Curso de Direito da UFSM, v. 8, p. 162- 171, 2013. Disponível em: <file:///C:/Users/Usuario/Downloads/825736331-1-SM.pdf>. Acesso em: 20 jan. 2017.

LYON, T.P.; MONTGOMERY, A.W. The Means and End of Greenwash. Organization \& Environment, v.28, n.2, p.223-249, 2015.

MAKOWER, J.A. Economia verde: Descubra as oportunidades e os desafios de uma nova era dos negócios. São Paulo: Gente, Cap. 2, p.17-20, 2009.

MACIAS-CHAPULA, C.A. O papel da informetria e da cienciometria e sua perspectiva nacional e internacional. Ciências da Informação, Brasília, v.27, n.2, p.134-140, 1998.

MOURA, G.G.; POMPEO, K.L.B. A influência do greenwashing nas atitudes do consumidor em relação às marcas que o adotam. Seminário de Iniciação Científica da ESPM- IX. Anais... São Paulo: 2015. 18p.

NABOUT, J.C.; CARVALHO, P.; UEHARA-PRADO M.; BORGES, P.P.; MACHADO, K.B.; HADDAD, K.B.; MICHELAN T, S.; CUNHA, H.F.; SOARES, T.N. Trends and biases in global climate change literature. Natureza \& Conservação, Goiânia, v.10, n.1, p.45-51, 2012.

OTTMAN, J.A. As novas regras do marketing verde: Estratégias, ferramentas e inspiração para o branding sustentável. São Paulo: M. Books do Brasil, Cap. 3, p.77-91, 2012.

PACHECO, C.A. O financiamento do gasto em P\&D do setor privado no Brasil e o perfil dos incentivos governamentais para P\&D. Revista USP, São Paulo, n.89, p.256-276, 2011.

PEREIRA, A.O.K.; HORN, L.F.D.R. (Org.). Relações de consumo: meio ambiente. Caxias do Sul: Educs, 2009. 232p.

PEREIRA, S.J.N.; AYROSA, E.A.T. Atitudes relativas a marcas e argumentos ecológicos: um estudo experimental. Gestão Organizacional, v.2, n.2, 2004. $12 p$. 
PETROBRAS- Mudança de rumos. 2017. Disponível em: $<$ http://www.petrobras.com/pt/magazine/post/mudanca-de-rumos.htm>. Acesso em 21 fev. 2017.

PINHEIRO, M.C. Marketing verde: Um estudo sobre a construção das estratégias competitivas da Natura Cosméticos. REVISTA DO CEDSPeriódico do Centro de Estudos em Desenvolvimento Sustentável da UNDB, v.1, n.2, 2015. 13p.

RIBEIRO, R.A.C.; EPAMINONDAS, L.M.R. Das estratégias do greenmarketing à falácia do greenwashing: a utilização do discurso ambiental no design de embalagens e na publicidade de produtos. Encontro Nacional da Anppas- V Anais... Florianópolis/SC, 2010. 18p.

RICARDO, E.C. Educação CTSA: obstáculos e possibilidades para sua implementação no contexto escolar. Ciência \& Ensino, Florianópolis: v.1, n.especial, 2007. 12p.

SIANO, S.A; VOLLERO, A.; CONTE, F., AMABILE, S. "More than words": Expanding the taxonomy of greenwashing after the Volkswagen. Journal of Business Research, v.71, p.27-37, 2017.

SILVA; A.M.M.; LOPES, W.G.R. Virtudes e falácias do marketing verde e consumo sustentável: A percepção de servidores públicos de instituições de ensino em Teresina, Piauí. REDE- Revista Eletrônica do PRODEMA, Fortaleza, v.8, n.2, p.77-91, 2014.

VANTI, N.A.P. Da bibliometria à webometria: uma exploração conceitual dos mecanismos utilizados para medir o registro da informação e a difusão do conhecimento. Ciências da Informação, Brasília, v.31, n.2, p.152-162, 2002.

VERBEEK, A.; DEBACKERE, K.; LUWEL, M. Measuring the progress and evolution in science and technology - $\mathrm{i}$ : The multiple uses of bibliometric indicators. International Journal of Management Reviews, v.4, n.2, p.179211, 2002. 